\title{
From Litigation Consulting to Research and Education
}

\author{
Oren Masory, Ph.D. \\ Florida Atlantic University, USA, masoryo@fau.edu
}

\begin{abstract}
The responsibility of an Expert Witness is to provide the defending attorney or the prosecutor with technical information supporting their argument. In times it is as simple as measuring the temperature of an oven. In others it might involve the review of a design and the figuring out the cause of failure or reconstruction of vehicle accident and the determination of the cause of injuries by simulating the motion of the occupants inside the vehicle during the collision. This paper describes a few cases, in which the author served as an expert witness and how they evolve to research activities and eventually propagate to his classes.
\end{abstract} projects.

Keywords - Senior project course, Forensic engineering

\section{INTRODUCTION}

Most expert witness professionals are dealing with relatively small claims related to Personal Injuries (PI) due to slip and fall, product liability, vehicle accidents etc. The typical expert witness is, in many cases, a person who has extensive experience in a very particular area, for example, in the cases of vehicle's accident reconstruction, many of the experts are police officers who investigated accidents during their employment. These experts are either self-employed or working for small outfits and as a result they have no time nor resources to perform any kind of experimentation or research. Large cases, like train derailing or aircraft crash, are investigated by state/federal organization or large companies. Also, most common PI issues, like slip and fall, ladder and vehicle accidents, are also studied by large insurance company who eventually have a financial stake in understanding these issues.

There are less than a dozen Forensic Engineering programs in U.S. universities [1], none offering a doctoral degree. Due to lack of funding in this area limited or very little research is performed in academic institutions in particular on topics related to PI. Moreover, these issues do not attract the intension of faculty members due the requirement put in front him with regard to tenure and promotion. In most universities the topic is not even introduced, and thus new generation of engineers are not aware of this area as a career opportunity.

By providing Expert Witness services in the PI arena, one is exposed to problems that otherwise he would never be aware off. Also, this hands on experience enhance his capacity to deal with issues such as the use of instrumentation in corrupted environment, improvisation to accommodate unexpected changes in the accident site, and other. From education point of view, many of these cases can be brought to class as examples or as a project in a design course. It is worth mentioning that usually students are interested in these examples since they are not textbook ones.

\section{SLIP AND FALL ON WALKING SURFACES}

The issue: Slip and Fall accidents are the leading cause of workers' compensation claims and medical costs, which amounts to approximately $\$ 70$ billion annually [2]. A report by The Bureau of Labor Statistics [3] states "Together, falls, slips, or trips accounted for 35 percent of the injuries and illnesses to heavy and tractor-trailer truck drivers in 2014." In [4] it is reported "falls on the same level is the second highest category of compensable loss and cost $\$ 6.7$ billion, according to the 2006 Liberty Mutual Workplace Safety Index". There are numerous reports on the subject but one that demonstrate the severity of this problem is reported in a study, performed by the National Floor Safety Institute (NFSI), that found that more than 3 million food service employees and over 1 million guests are injured annually as a result of restaurant Slips and Falls accidents. These injuries are increasing at a rate of about $10 \%$ annually [5]. As a result, one can realize that there numerous law suits related to slip and fall. The consultant responsibility, in these cases, is to determine the cause for the incidents. A major part of his investigation is to determine the Static Coefficient Of Friction (SCOF) of the surface on which the person slipped. Most of the time consultants are using off the shelf commercial slip-meters for this purpose.

All slip-meters are using, directly or indirectly, a simple test called "pull test" (see Figure 1). A foot, made of a standard material usually Neolite (material that imitates the characteristics of leather soles), is attached to the bottom of a block of weight $W$. The block is placed on the horizontal surface being tested, and a pulling force, $F$, is applied to the block. At any time the magnitude of the pulling force is equal to the friction force acting between the block and the surface. The pulling force is increased to the point that block starts to move (impending motion). At that instant the friction force assumes its maximum value and the $\mathrm{SCOF}, \mu_{\sigma}$, is given by:

$$
\mu_{g}=\frac{F_{\max }}{N}
$$

Eq. 1 was established by Charles-Augustin de Coulomb (1785) who extensively study dry friction occurring between

Digital Object Identifier (DOI):

http://dx.doi.org/10.18687/LACCEI2019.1.1.250

ISBN: 978-0-9993443-6-1 ISSN: 2414-6390

$17^{\text {th }}$ LACCEI International Multi-Conference for Engineering, Education, and Technology: "Industry, Innovation, And Infrastructure for Sustainable Cities and Communities", 24-26 July 2019, Jamaica. 
contacting surfaces in the absence of a lubricating fluid. However, Eq. 1 does not specifies any parameters needed to be satisfied while performing the test. These include: minimum contact pressure, contact area, contact surface shape and foot's surface texture (e.g. grooves. As a result, commercial slip meters differ one from the other with respect to these parameters.
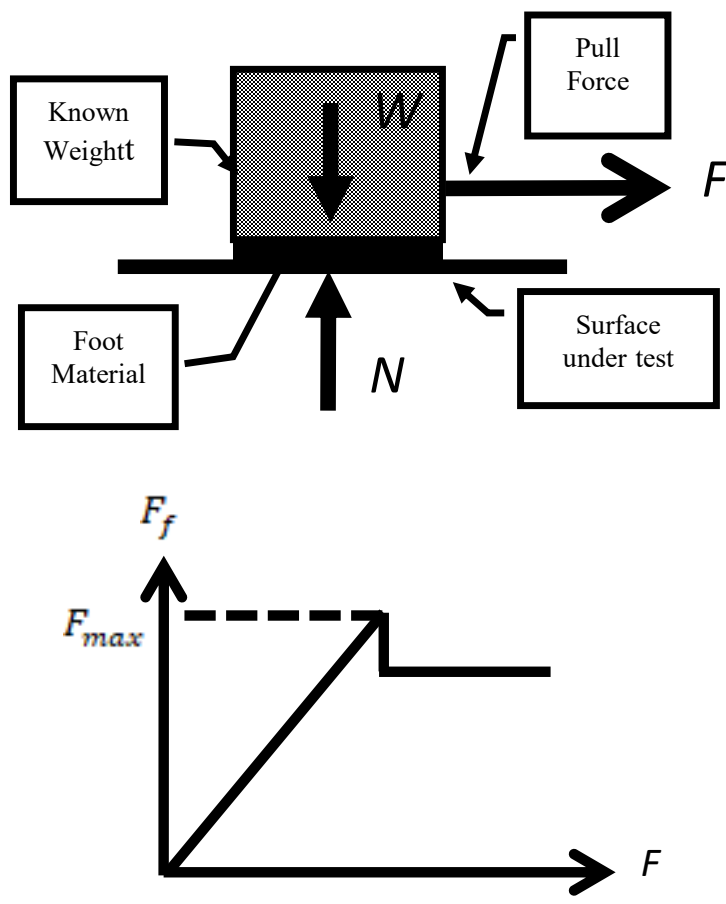

Fig. 1 Pull test

Research: A small research work in which a small set of experiments were performed to determine the effect of these parameters on the value of the SCOF with the following results:

1. Figure 2 illustrates that a minimum contact pressure is required in order to have a reliable value of the SCOF.

2. Table 1 shows the values of the SCOF where circular and square feet, of the same contact area and under the same contact pressure, were used. It is clear that there is difference between the two SCOFs.

3. The effect of contact area on the value of the SCOF, as shown in Table 2, is minor.

4. The effect of grooves in the foot has a major effect on the SCOF as seen in Figure 3. Similar results were reported in a research related to traction capabilities of shoes' soles with different grooves [6].
TABLE I

CIRCULAR VERSUS SQUARE FEET

\begin{tabular}{|c|c|c|c|c|}
\hline Direction & \multicolumn{2}{|c|}{ North } & \multicolumn{2}{c|}{ South } \\
\hline Shape & Square & Circle & Square & Circle \\
\hline Mean & 0.285 & 0.281 & 0.348 & 0.328 \\
\hline $\begin{array}{c}\text { Variance } \\
* 10^{3}\end{array}$ & 0.281 & 0.676 & 0.0621 & 0.897 \\
\hline
\end{tabular}

TABLE II

TESTS' RESULTS FOR DIFFERENT CONTACT AREAS

\begin{tabular}{|l|c|c|}
\hline & \multicolumn{2}{|c|}{ Contact area[sqin] } \\
\hline & 9 & 3 \\
\hline Contact Pressure $[\mathrm{kPa}]$ & 28.828 & 27.918 \\
\hline Mean & 0.386 & 0.387 \\
\hline Variance & 0.000106 & 0.000186 \\
\hline
\end{tabular}

\section{COF versus Contact Pressure}

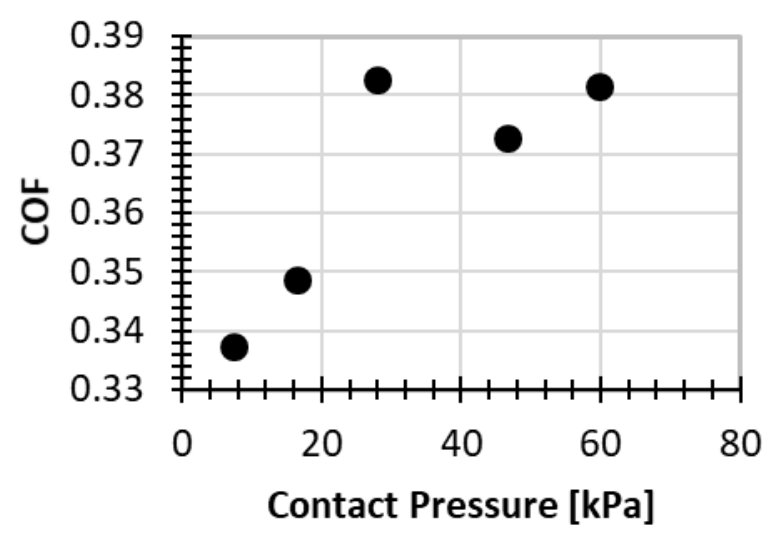

Fig. 2 Effect of contact pressure on the value of SCOF.

The above issues will surface in court since commercial slip meters are different from each other with respect to the above parameters. An example for deviations in the readings of SCOF obtained by four different commercial slip meters, that were validated by ASTM F2508-13 standard [7], are shown in Figure 4. The dash line demonstrates a case where the classification of the surface slipperiness varies from one tribometer to another from "very slippery" to "acceptable slippery" [8].

Education: This topic was discussed in Senior Design class and students were asked to suggest solutions. Variety of solutions, in which the test is executed fully automatically, using a microcontroller, which also control the pulling speed, sample and record the pulling force, were proposed:

1) A simple linear pull using square foot (Figure 6a). 
2) A rotational "pull test", where the rotational speed and torque are measured, and the foot is has shape of a disk (Figure 6b). The idea was to measure the average SCOF in all possible pulling direction (rather 4 direction as specified in ASTM F2506-13).

$3)$ A rotational arm with an interchangeable foot. (Figure $6 c)$.

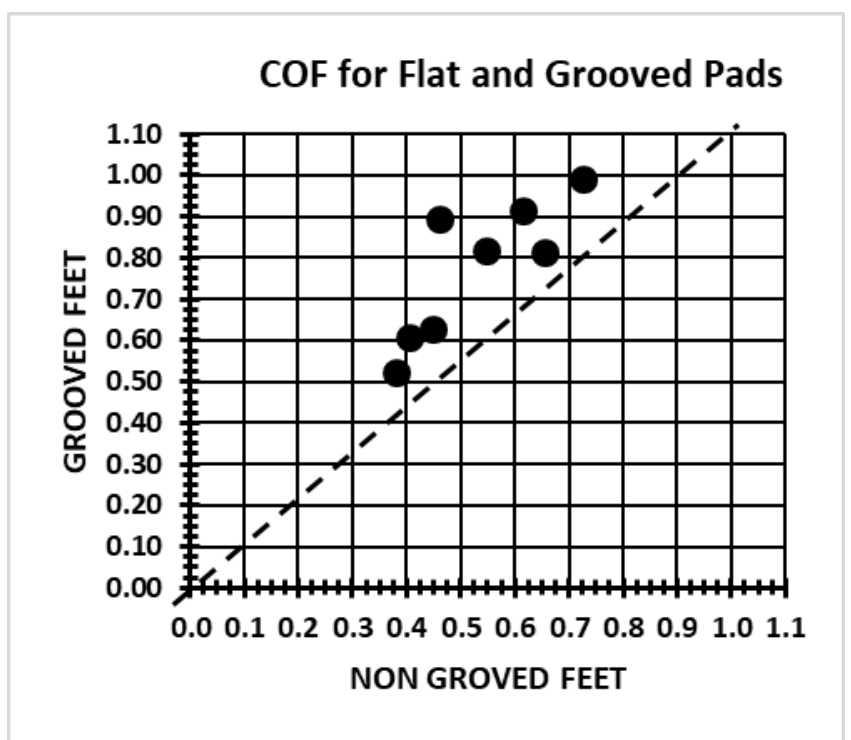

Fig. 3 The effect of grooves on the SCOF value.

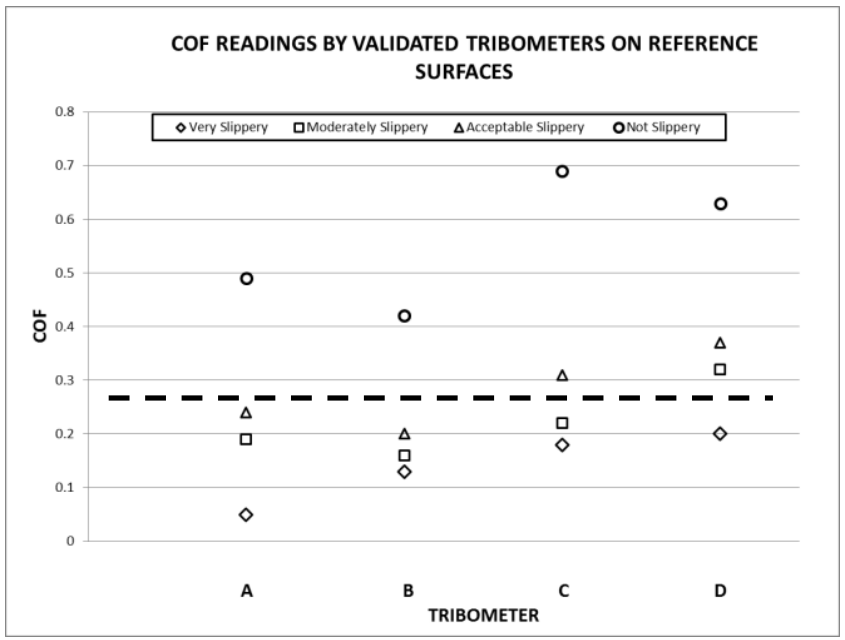

Fig. 4 COF measurements of the reference surfaces by the 4 validated tribometers.

\section{GOLF CART EJECTION ACCIDENTS}

The issue: The state of Florida is blessed with 1534 golf courses [9] and probably over 250,000 golf cart (extrapolating from the fact that only The Villages there are more than 50,000 golf carts [10-11]). Top speed of a golf cart is 15 [mph] while for Low Speed Vehicles (LSV), which, in many communities allowed to share city streets of speed limit of 35 [mph], is $25[\mathrm{mph}]$. It was estimated that there were approximately 48,255 golf cart related injuries during the years 2002-2005 [666]. The Consumer Product Safety Commission (CPSC) estimated that between the years 2002 and 2011 an annual average of 13,740 were injured severely enough to be sent to the hospital while using golf carts [12]. Overwhelming majority, $(38.3 \%)$ of these injuries are due to passenger ejection, and more than twice as likely to result in head or neck injury, and more than six times as likely to result in concussion [13]

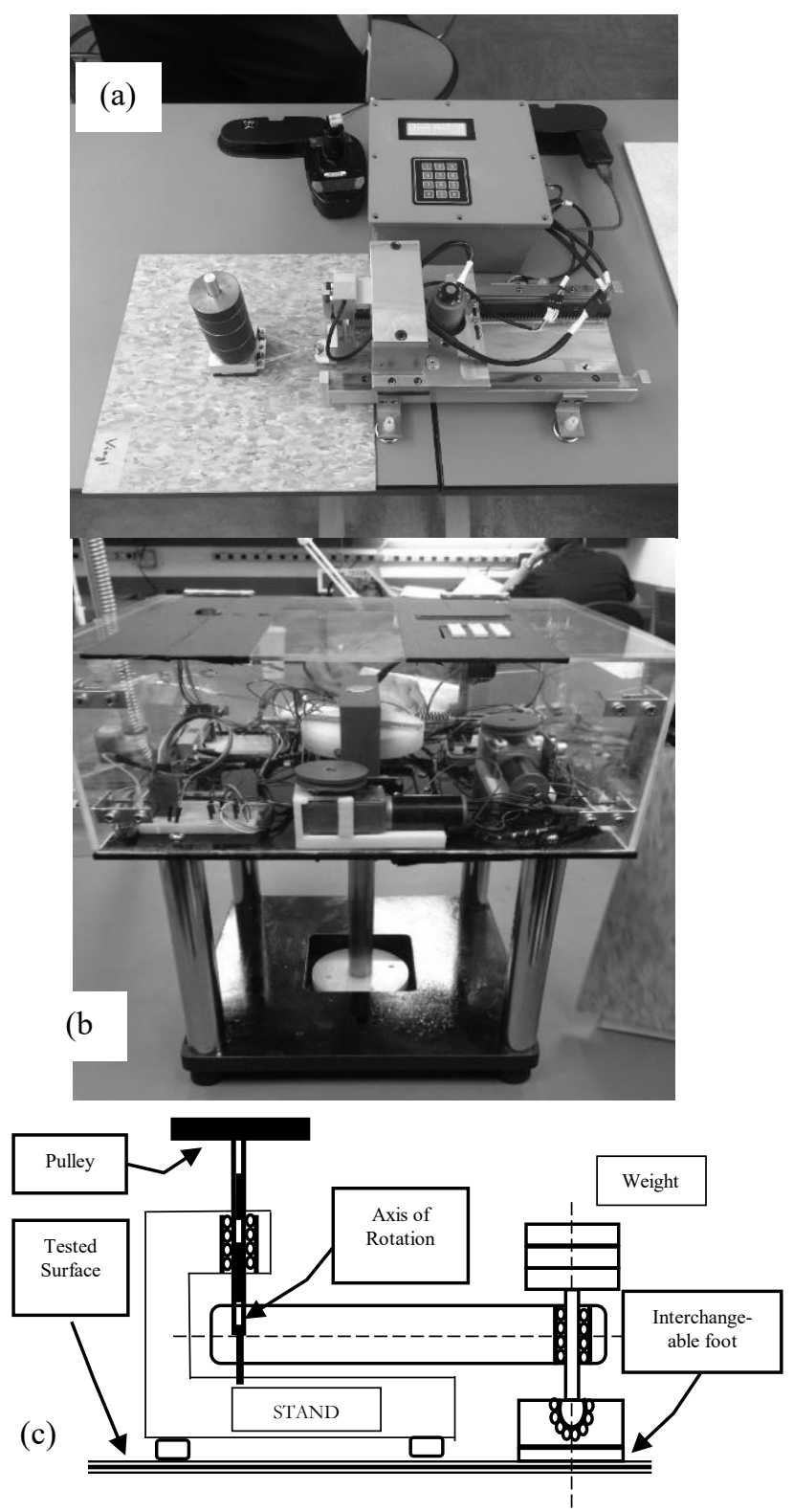

Fig. 5 Students' projects. 
Research: Being involved in the investigation of ejection accidents, in particular of rear facing passengers, a limited research program was initiated. A commercial golf cart was instrumented with accelerometers, mounted at the front and rear passengers' seats, and a set of runs with different driving speed and turning radii was performed. The acceleration signals were sampled at $100[\mathrm{~Hz}]$ and recorded. The cart geometry, in particular the dimension and the location of the hip restraints, was model using Articulated Total Body (ATB) simulation tool. The passenger was modelled by GBOD [14] and was incorporate into the ATB simulation. At this point, the acceleration signals, obtained by the actual driving, were used to "Drive" the simulated cart and the motion of the passenger was observed. Analysing the cases where the passengers were ejected (see Figure 6), provide the maximum allowed acceleration given the geometry of the hip restraint [15]. In addition, modifications to the restraint provided at the rear of the cart were proposed.

Education: In this study one senior student was involved. He was supported by the university Undergraduate Research Program. In the Mechanical Engineering Las course there was an opportunity to engage students in these kind of measurements. In one lab assignment students were asked quantify the comfort level of a passenger as the vehicle crosses a standard street bump at different speeds. They had to measure and record the three acceleration components using their smart phones and find correlation with comfort level expressed by the driver in scale 1 to 5 .

\section{EVENT DATA RECORDER AND COLLISION ANALYSIS}

The issue: In the past the impact force and the energy absorbed by the vehicle during collision were estimated by measuring the actual deformation of the crush and using experimental stiffness coefficients. It is obvious that these measurements are not accurate and their accuracy, in spite of a standard procedure, depends on the person who took them. Therefore the estimation of the impact force and the absorbed energy, which are indicators for the severity of the accident and the inflected injuries, will different from one expert to the other.

Once airbags are installed, the airbag control module serves as an Event Data Recorder (EDR). The module includes an accelerometer, sampled at $100[\mathrm{~Hz}]$, and the reading are used to determine whether or not to deploy the airbag. If the airbag was deployed, the acceleration readings are recorded and can be retrieved later for the reconstruction of the accident.

Although there is a large volume of publications related to this topic, there are still unresolved issues that need clarification, for example:

1. Statistically quantify the errors in the crush measurements

2. The airbag module records the acceleration only if the airbag is deployed. Therefore, collision at low speed, usually below $30[\mathrm{mph}]$, has to be analyzed in different way.

3. Which of the two methods is more reliable

4. Any other analysis method will provide more accurate results
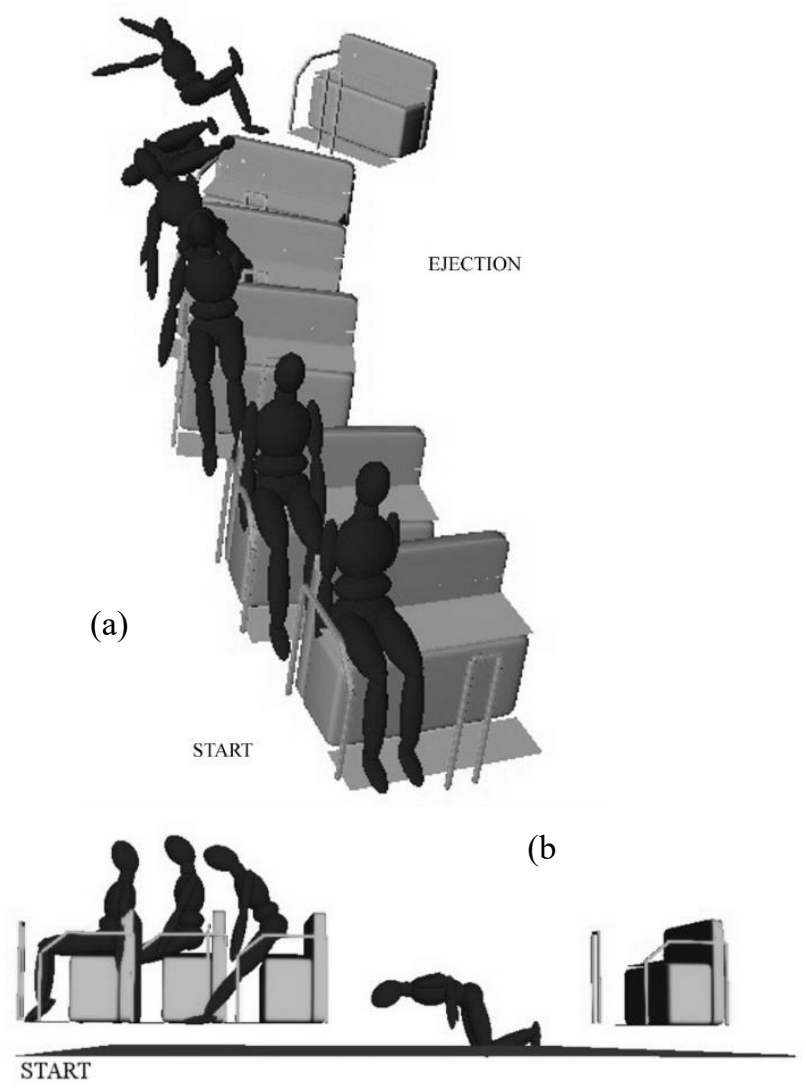

Fig. 6 Ejection from golf cart. (a) Sharp turn; (b) High acceleration

Research: The opportunity to determine the uncertainty in variety of measurements, performed during accident reconstruction, presented itself in WREX 2000 conference that took place in Texas A\&M University. Attendees, professional accident reconstructionists, were asked to measure skid marks length, drag coefficient, yaw marks, residual crush of a vehicle that was involved in frontal collision. Figure 7 [16]. illustrates the crush measurement obtained by 17 attendees. The average crush depth recorded by the participants ranged from 11.0" to 34" with an average of 19.4 " and standard deviation of 5.2". The reported length of the damaged area ranged from 48 " to 78 " with an average of $62.4 "$ and standard deviation of 9.9". The results, with the uncertainty of the stiffness coefficient, make this method very unreliable and any expert testimony will be questioned and might be dismissed.

A different approach was proposed in [17] in which a special network called "Abductive Network" (AIM) which in a

$17^{\text {th }}$ LACCEI International Multi-Conference for Engineering, Education, and Technology: "Industry, Innovation, And Infrastructure for Sustainable Cities and Communities", 24-26 July 2019, Jamaica. 
way similar to Neural Networks but the function implemented at each node is a polynomial where the coefficients are found during the training. Using crush depth results from 50 crush tests the impact force and the crush energy were calculated using CRASH 3 (commercial software package) and compared with the results obtained by the AIM (see Figure 8). As shown the network solution is by far more conservative.

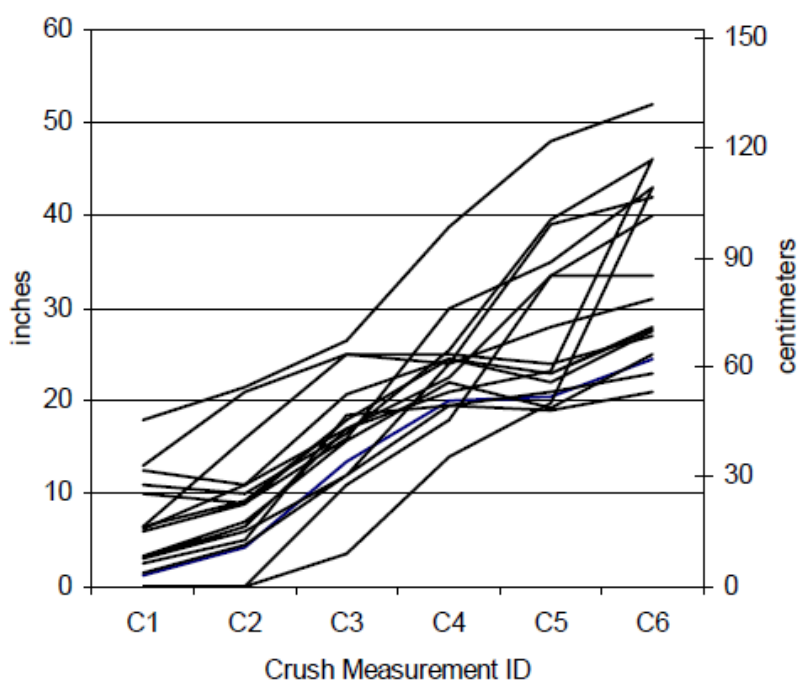

Fig. 7 Residual crush measurements profiles

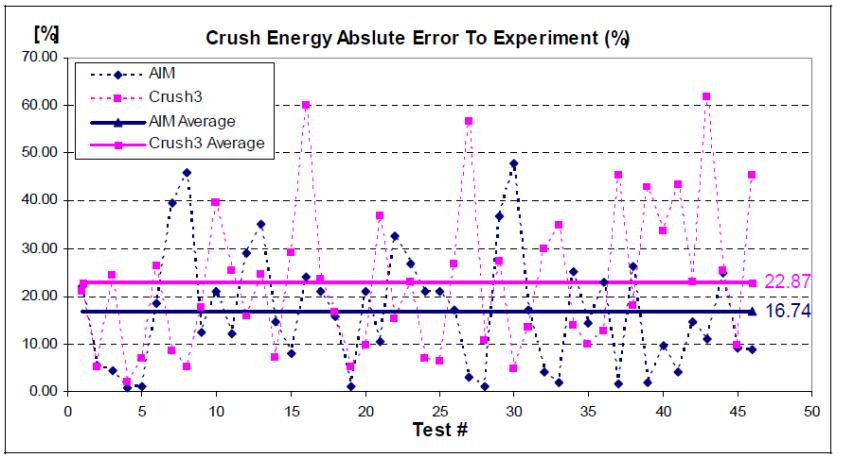

Fig.8 Crush energy absolute error.

Education: First, the work with Abductive Networks was partially performed by French undergraduate students who come to FAU for a period of 4-6 months as required by their degree program. In Numerical Methods class, students are asked to down load acceleration measurements from crash test that were performed by the National Highway Transportation Safety Administration (NHTSA). Then they have filter the signal using low pass and moving average filters. Then they integrate the signal, using any of the numerical integration methods cover in class, to find the velocity and to determine the coefficient of restitution. With one more integration the displacement of is found and compared to the actual crush depth given in the same database. Deviation between the two should be explained.

\section{CONCLUSIONS}

Expert witness subject includes a wide spectrum of topics from biology, fire investigations, patent infringement to computer science. It is perceived that PI investigations are very limited in scope which is far away from reality. A good expert witness in this area should master engineering concept from many disciplines mechanical, Electrical, Material, Biomechanics and others. At times it is very challenging problem that requires some experimentation, research or at least to find relevant information. Almost in all cases the investigation is taking place at the accident site which present many difficulties, due time delay and contamination, which do not exist in laboratory environment.

At the completion of the accident the expert is facing other challenges: 1) Present his finding to a jury who are nor familiar with issue; and 2) Defend his position in cross examination that might become very intimidated. Most important, working for the plaintiff, one should remember that the opinions expressed by the Expert Witness determine the financial outcome of the law suites effecting the plaintiff's future quality of life.

Whatever the reason is, real or perception, the profession does not attract engineering students, as reflected by the number of programs offered in the US. This might be due to lack of interest or the credit hour availability, the result is the same.

\section{REFERENCES}

[1] http://study.com/articles/Schools_with_Forensic_Engineering Programs_How_to_Choose.html

[2] National Floor Safety Institute, https://nfsi.org/

[3] BLS News Letter USDL 15-2205, November 19, 2015

[4] Liberty Mutual Research Institute for Safety, Vol. 10, No. 3,

[5] Slips and Falls Study: Objective Auditing Techniques to Control Slips and Falls in Restaurants, CNA June 2007. Autumn 2007.

[6] Kai Way Li, Chin Jung Chen, "Effects of tread groove orientation and width of the footwear pads on measured friction coefficients", Safety Science, Vol 43, 2005.

[7] ASTM 2508 "Standard Practice for validation, calibration, and certification of walkway slip meters using reference surface".

[8] Comment on

[9] https://www.golflink.com/golf-courses/state.aspx?state=fl

[10] www.insidethebubble.co/82-cool-facts-the-villages/

[11] Mcgwin G. et. al, "Incidence of golf cart related injuries in the US", The Journal of TRAUMA, Infection and Critical Care, Vol 64, June 2008.

[12] CPSC- National Electronic Injury Surveillance System, 2011, www,cpsc.gov/Neiss/oracle.html

[13] Watson, D. Mehan, T., Smith, G, "Golf cart-related injuries in the U.S.", American Journal of Preventive Medicine, Vol 35, July 2008.

[14] ARticulated Total Body Model Version V; User's Manual, HTTPS://WWW.RESEARCHGATE.NET/PUBLICATION/235173886_ARTIC ULATED_TOTAL_BODY_MODEL_VERSION_V_USER'S_MANUAL.

$17^{\text {th }}$ LACCEI International Multi-Conference for Engineering, Education, and Technology: "Industry, Innovation, And Infrastructure for Sustainable Cities and Communities", 24-26 July 2019, Jamaica. 
[15] K. Schau, O. Masory, "Ejection of a Rear Facing, Golf Cart Passenger", Journal of Accident Analysis and Prevention, Vol. 59, October 2013, pp. 574-579.Kyle

[16] Wade Bartlett, William Wright, Oren Masory, Raymond Brach, Al Baxter, Frank Navin, Bruno Schmidt, "Evaluating the Uncertainty in Various Measurement Tasks Common to Accident Reconstruction", SAE Technical paper 2002-01-0546

[17] O. Masory, N. Putod, "Determination of Impact Force and Crush Energy Using Abductive Networks", Proc. $20^{\text {th }}$ Florida Conference on Recent Advances in Robotics, May 31-June 1, 2007.

$17^{\text {th }}$ LACCEI International Multi-Conference for Engineering, Education, and Technology: "Industry, Innovation, And Infrastructure for Sustainable Cities and Communities", 24-26 July 2019, Jamaica. 